\title{
ASSESSMENT OF ORAL HEALTH RELATED QUALITY OF LIFE FOR CHILDREN WITH SPECIAL HEALTH CARE NEEDS AFTER ORAL REHABILITATION UNDER GENERAL ANAESTHESIA (CROSS SECTIONAL STUDY)
}

\author{
Mohammed M. Metwally ${ }^{1 *} B D S$, Aly A. Sharaf ${ }^{2} P h D$, Niveen S. Bakry ${ }^{2} P h D$ \\ ABSTRACT
}

INTRODUCTION: Children with Special Health Care Needs (CSHCN) can be at increased risk of unmet dental services. Dental treatment under General Anesthesia (GA) may be a safe and effective treatment for CSHCN. Assessing Oral Health Related Quality of Life (OHRQoL) of CSHCN could enable the evaluation of the oral health state and treatment efficiency after oral rehabilitation under GA.

OBJECTIVES: To assess change in oral health related quality of life among children with special health care needs before and after oral rehabilitation under general anesthesia.

MATERIALS AND METHODS: A cross-sectional study with a sample of 47 parents/caregivers of CSHCN who were scheduled for oral rehabilitation under GA at the Faculty of Dentistry, Alexandria University. Parents/caregivers responded to a selfcompleted Child Oral Health-Related Quality of Life questionnaire (COHQoL). It consisted of Parental- Caregiver Perceptions Questionnaire (P-CPQ) and Family Impact Scale (FIS) which, was completed before and at 1 month after the oral rehabilitation. RESULTS: The impact on OHRQoL was reportedly negative before oral rehabilitation under GA but it improved significantly $(p=0.001)$ in all aspects postoperatively with overall scores for P-CPQ section ranged from 12.0 to 45.0 and a mean of $30.2 \pm 7.7$ preoperative and it declined post-operatively to range from 0.0 to 39.0 and a mean of $15.9 \pm 11.4$. For FIS section scores ranged from 3.0 to 23.0 and a mean of $13.9 \pm 4.5$ preoperative and declined post-operatively to range from 0.0 to 21.0 and a mean of $7.3 \pm$ 6.0 .

CONCLUSIONS: Oral rehabilitation of CSHCNs under GA markedly improved their OHRQoL as well as their families. KEYWORDS: Oral health related quality of life, children with special health care needs, general anesthesia.

1. Resident of Pediatric Dentistry, Department of Pediatric Dentistry and Dental Public Health, Faculty of Dentistry, Alexandria University, Egypt. 2. Professor of Pediatric Dentistry, Department of Pediatric Dentistry and Dental Public Health, Faculty of Dentistry, Alexandria University, Egypt.

*Corresponding author:

E-mail: m_metwally89@yahoo.com

\section{INTRODUCTION}

Dental caries is one of the most common health problems affecting children (1). It is considered as the 10th most prevalent disease worldwide, affecting 621 million children globally (2). It is observed in developing countries that oral diseases are more common than in industrialized countries, as a result of difficult access to clean fluoridated water, malnourishment and unhygienic environment which are risk factors to both oral and general health. Moreover, preventive or restorative dental care is not a priority and for many people treatment is often limited to pain relief and emergency care (3).

According to the American Academy of Pediatric Dentistry (AAPD) 2019, Special Health Care Needs (SHCN) was defined as "any physical, developmental, mental, sensory, behavioral, cognitive, or emotional impairment or limiting condition that requires medical management, health care intervention, and/or use of specialized services or programs. The cause of the condition may be congenital, developmental, or secondary to disease, trauma, or environmental cause and may lead to limitations in performing daily selfmaintenance activities or significant limitations in a major life activity (4).

The care of Children with Special Health Care Needs (CSHCN) is becoming a significant public health issue. Many of these children are medically compromised, require services beyond those that typically developing children need, and with a considerable proportion of the pediatric health care budget (5). 
According to World Health Organization (WHO) in 2011, individuals with Special Health Care Needs comprise $11.8 \%$ of the population in developed countries and $18 \%$ in developing countries (6). A community-based survey was conducted in Alexandria 2017 by Wahdan and El-Nimr using multistage cluster sampling technique. They found that the prevalence of CSHCN was $12.2 \%$ and the higher prevalence of CSHCN was in males, with a male to female ratio of $1.25: 1$. It was about $23 \%$ of the CSHCN, cognitive impairments about $16.4 \%$ and impaired mobility 9.8\% (7).

The CSHCN are at increased risk for acquiring dental disease (8). Neuromuscular, acquired or genetic disorders in many cases cause alterations or defects in skeletal and facial structures (9). Many studies (10-12) showed that children with special health care needs generally receive less restorative care than their nondisabled counterparts and that nearly $80 \%$ of children with disabilities have untreated caries (13).

The oral health status of CSHCNs is influenced by various sociodemographic factors such as age, living conditions, severity of impairment, special diets and the type of medication taken daily (14). In addition, caregivers of CSHCN face an increased burden due to the demands of taking care of their children which may lead to neglect regarding their oral health as this is not regarded as a priority (15). Also, caregivers of CSHCNs often face difficulty when carrying out their daily oral hygiene requirements as children can be uncooperative and resist care (16).

Dental treatment under general anesthesia (GA) may be required to deliver effective treatment for dental caries when other behavioral or pharmacological management techniques fail (17). Treating CSHCN under GA enables high-quality dental care by eliminating the factors of poor cooperation and lack of compliance $(18,19)$. It offers a fast, safe, comfortable and convenient method for both the patient and the dentist (20).

Parental/caregiver perceptions of children's Oral Health Related Quality of Life (OHRQoL) are especially important for CSHCN due to the fact that many of these patients are with limitations in their cognitive capacities and communication skills. These families also come to face great emotional and financial strain in trying to gain access to all the necessary health services for their children (21).

A number of validated scales for OHRQoL measures are available, not only for use with adults but also with children (22). The Child Oral Health-Related Quality of Life (COHRQoL) questionnaire is a method of measuring OHRQoL and it includes ParentalCaregiver Perceptions Questionnaire (P-CPQ) which was developed by Jokovic et al in 2003 (23) and the Family Impact Scale (FIS) which was developed by
Locker et al in 2002 (24). Both of them were directed to use parental informants rather than questioning young children directly (25).

The increased attention towards the CSHCNs led to the focus on their oral health related quality of life and treatment efficiency after oral rehabilitation and whether these findings are unique to the studied population or can be generalized to other populations. However, limited information is available on the effect of oral rehabilitation under GA of CSHCN on their oral health related quality of life in Egypt. Hence, the objective of this study was to assess changes in the oral health related quality of life among children with special health care needs before and 1 month after oral rehabilitation under general anesthesia performed at Department of Pediatric Dentistry, Faculty of Dentistry, Alexandria University. The null hypothesis of this study was that, there is no improvement of the OHRQoL of CSHCN after oral rehabilitation under GA.

\section{MATERIALS AND METHODS}

Ethical approval was obtained from the research ethics committee, Faculty of Dentistry, Alexandria University before beginning of the study. Informed consent was signed by parent/caregiver of CSHCNs before participation in the study. The study design was a cross-sectional analytical study (figure 1) based on validated pre and post-operative questionnaires (25). The study took place at the Department of Pediatric Dentistry and theatres at Faculty of Dentistry, Alexandria University where general anesthesia procedures were performed.

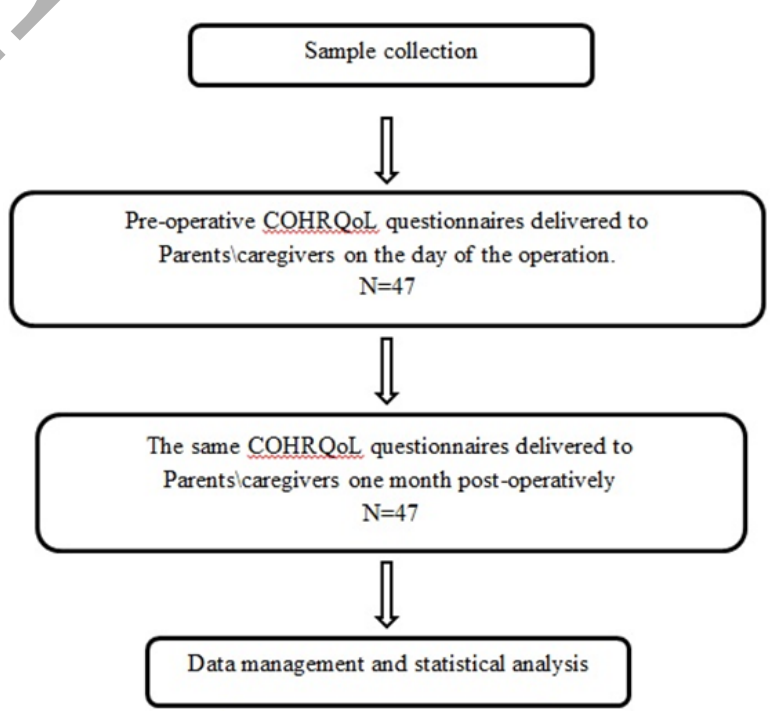

Figure (1): Flow chart of research

The sample consisted of Parentslcaregivers of CSHCNs who were scheduled to undergo oral rehabilitation under GA between midyear 2017 
through 2018 with children age from 3 to 8 years. The minimal sample size was calculated based on a previous study by El-Meligy et al. (20) by using a power of $80 \%$ and level of significance $95 \%(\alpha=0.05)$ was found to be 38 with an anticipated drop-out rate of $20 \%$ minimal required sample size increased to 45 CSHCN. The inclusion criteria were parents\caregivers of CSHCNs who were scheduled to undergo oral rehabilitation under GA, willing to participate and signing an informed consent. Exclusion criteria included presence of uncontrollable medical conditions; patients who were classified by American Society of Anesthesiologists (ASA) as Class III and Class IV (27); Children whose parents had no available source of communication to enable post-operative contact for follow up visit; Illiterate parents unable to complete the questionnaires.

Parents/caregivers of CSHCN who were scheduled to undergo oral rehabilitation under GA were interviewed on the day of operation. Diagnosis of dental caries was done on visual evidence after drying and removing the debris from the teeth with the help of an explorer and mirror according to the modified World Health Organization guidelines (28).

Pre-operatively, the investigator explained the Child Oral Health Related Quality of Life (COHRQoL) questionnaires. The Arabic version of the questionnaire was validated and tested for reliability by Lotfy (26) in 2014 who reported that the COHRQoL could be an effective tool to measure the OHRQoL in young Egyptian children. Parents/caregivers filled it on the day of GA. It was answered according to the child's oral state within the 3 past months, which included 2 sections:

a. Parental-Caregiver Perceptions Questionnaire (PCPQ) section. It consisted of 16 items (closed-ended questions) which are grouped into four domains: Oral symptoms items $(\mathrm{n}=4)$, functional limitations items $(n=4)$, emotional wellbeing $(n=4)$ and social wellbeing $(n=4)$.

b. The Family Impact Scale (FIS) section. It consisted of 8 items which are grouped into three subscales/domains: parental/family activity $(n=4)$, parental emotions items $(n=2)$ and family conflict $(n=2)$.

One month post-operatively, the same COHRQoL questionnaires were completed by the participants. If they failed to attend that appointment, the questionnaire was filled by them on telephone by the investigator. Each response was scored as follows: (0) never; (1) once/twice; (2) sometimes/often; (3) every day/almost every day; (4) do not know. The score was calculated by summing the scores of each domain separately. The total score was obtained by summing the responses to each section, lower scores indicated better OHRQoL.

\section{Statistical analysis}

- Data were collected and entered to the computer using SPSS (Statistical Package for Social Science) program for statistical analysis (version 21). The pre-operative and post-operative scores were compared using Wilcoxon Signed Ranks test (29).

- Kolmogorov-Smirnov test of normality revealed significance in the distribution of most of the variables, so the non-parametric statistics was adopted.

- Percentage change was calculated as follows:

Percentage change $(\%)=($ Measurement $($ post)Meaurement (pre)) / (Meaurement (before)) x 100 An alpha level was set to $5 \%$ with a significance level of $95 \%$, and a beta error accepted up to $20 \%$ with a power of study of $80 \%$.

\section{RESULTS}

The total study population consisted of 49 caregivers of CSHCN who were scheduled to undergo full mouth rehabilitation under general anesthesia at Pediatric Dentistry Department, Faculty of Dentistry, Alexandria University between July 2017 and June 2018. The follow-up response rate was $95.91 \%$ with 47 participants coming for follow up and completing the questionnaire (one participant refused to complete the study, the other participant could not be contacted during the study period).

The pre-operative and post-operative scores for different domains were compared using Wilcoxon Signed Ranks Test. It showed a significant postoperative improvement in all 4 domains of P-CPQ at $\mathrm{p}=0.001$ (Table 1). Also, the total score of P-CPQ section pre-operative and post-operative was compared. It showed a significant post-operative improvement at $\mathrm{p}=0.001$ (table 2).

Table (1): The Pre-operative and Post-operative scores of P-CPQ domains and the percentage change

\begin{tabular}{|l|c|c|c|c||}
\hline $\begin{array}{l}\text { P-CPQ } \\
\text { domain }\end{array}$ & $\begin{array}{l}\text { Oral } \\
\text { symptoms }\end{array}$ & $\begin{array}{l}\text { Functional } \\
\text { limitations }\end{array}$ & $\begin{array}{l}\text { Emotional } \\
\text { well-being }\end{array}$ & $\begin{array}{l}\text { Social well- } \\
\text { being }\end{array}$ \\
\hline $\begin{array}{l}\text { Pre- } \\
\text { operative: } \\
\text { Mean } \pm S D\end{array}$ & $8.5 \pm 2.5$ & $7.9 \pm 2.8$ & $8.6 \pm 2.8$ & $5.2 \pm 3.3$ \\
\hline $\begin{array}{l}\text { Post- } \\
\text { operative: } \\
\text { Mean } \pm S D\end{array}$ & $3.9 \pm 3.6$ & $4.2 \pm 3.3$ & $4.6 \pm 3.8$ & $3.3 \pm 2.8$ \\
\hline $\begin{array}{l}\mathbf{Z}_{\text {(wsR) }} \\
\text { P value }\end{array}$ & $\begin{array}{l}\mathrm{Z}=5.467 \\
<0.001^{*}\end{array}$ & $\begin{array}{l}\mathrm{Z}=4.970 \\
<0.001^{*}\end{array}$ & $\begin{array}{l}\mathrm{Z}=5.005 \\
<0.001^{*}\end{array}$ & $\begin{array}{l}\mathrm{Z}=3.614 \\
<0.001^{*}\end{array}$ \\
\hline $\begin{array}{l}\text { Percentag } \\
\text { e change: } \\
\text { Mean } \pm S D\end{array}$ & $-53.5 \pm 39.6$ & $-44.0 \pm 52.9$ & $-44.2 \pm 44.6$ & $-24.1 \pm 105.6$ \\
\hline
\end{tabular}

WSR: Wilcoxon Signed Ranks Test

*: Statistically significant $(\mathrm{p}<0.05)$

NS: Statistically not significant $(\mathrm{p} \geq 0.05)$ 
Table (2): The total scores and percentages, pre and post-operatively and percentage change of percent for P-CPQ and FIS sections.

\begin{tabular}{|c|c|c|c|c|c|c|}
\hline & $\mathbf{n}$ & $\begin{array}{l}\text { Min- } \\
\text { Max }\end{array}$ & $\begin{array}{l}\text { Mean } \\
\pm \text { SD }\end{array}$ & $\begin{array}{c}\text { Medi } \\
\text { an }\end{array}$ & IQR & $\begin{array}{c}\text { Test of } \\
\text { signific } \\
\text { ance }\end{array}$ \\
\hline \multicolumn{7}{|c|}{ Total score of P-CPQ } \\
\hline $\begin{array}{l}\text { (pre- } \\
\text { operative) }\end{array}$ & 47 & $\begin{array}{l}12.0- \\
45.0\end{array}$ & $\begin{array}{c}30.2 \pm \\
7.7\end{array}$ & 31.0 & $\begin{array}{l}26.0- \\
35.0\end{array}$ & \multirow{2}{*}{$\begin{array}{c}\mathrm{Z}_{(\mathrm{WSR})}= \\
5.464 \\
\mathrm{p}=0.00 \\
0^{*}\end{array}$} \\
\hline $\begin{array}{l}\text { (post- } \\
\text { operative) }\end{array}$ & 47 & $\begin{array}{l}0.0- \\
39.0\end{array}$ & $\begin{array}{c}15.9 \pm \\
11.4\end{array}$ & 17.00 & $6.0-28.0$ & \\
\hline $\begin{array}{l}\text { Total score } \\
\text { of P-CPQ } \\
\text { percentage } \\
\text { change of } \\
\text { percent }\end{array}$ & 47 & $\begin{array}{c}-100.0- \\
19.2\end{array}$ & $\begin{array}{c}-48.6 \pm \\
36.8\end{array}$ & -54.8 & $\begin{array}{c}-82.4- \\
-20.0\end{array}$ & \\
\hline \multicolumn{7}{|c|}{ FIS total score } \\
\hline $\begin{array}{l}\text { (pre- } \\
\text { operative) }\end{array}$ & 47 & $\begin{array}{l}3.0- \\
23.0\end{array}$ & $\begin{array}{c}13.9 \pm \\
4.5\end{array}$ & 13.0 & $\begin{array}{c}11.0- \\
16.0\end{array}$ & \multirow{2}{*}{$\begin{array}{c}\mathrm{Z}_{(\mathrm{WSR})}= \\
4.966 \\
\mathrm{p}=0.00 \\
0 *\end{array}$} \\
\hline $\begin{array}{l}\text { (post- } \\
\text { operative) }\end{array}$ & 47 & $\begin{array}{l}0.0- \\
21.0 \\
\end{array}$ & $\begin{array}{c}7.3 \pm \\
6.0 \\
\end{array}$ & 7.0 & $2.0-12.0$ & \\
\hline $\begin{array}{l}\text { FIS total } \\
\text { score } \\
\text { percentage } \\
\text { change of } \\
\text { percent }\end{array}$ & 47 & $\begin{array}{c}-100.0- \\
66.7\end{array}$ & $\begin{array}{c}-47.4 \pm \\
42.8\end{array}$ & -60.9 & $\begin{array}{c}-80.9- \\
12.5\end{array}$ & \\
\hline
\end{tabular}

$\mathrm{n}$ : Number of patients

Min-Max: Minimum - Maximum

IQR: Inter-quartile range

WSR: Wilcoxon Signed Ranks Test

*: Statistically significant $(\mathrm{p}<0.05)$

NS: Statistically not significant $(\mathrm{p} \geq 0.05)$

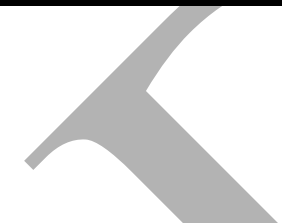

The total scores of each domain of FIS were compared between the pre-operative and postoperative scores using Wilcoxon Signed Ranks Test. It showed a significant post-operative improvement in all 3 domains of FIS at $p=0.001$ (Table 3 ). The total score of FIS pre-operative and post-operative, there was a significant post-operative improvement at $\mathrm{p}=0.001$ (table 3).

Table (3): Total pre and post-operative scores FIS domains and percentage change

\begin{tabular}{||l|c|c|c||}
\hline FIS domains & $\begin{array}{c}\text { Parental- family } \\
\text { activity }\end{array}$ & $\begin{array}{c}\text { Parental } \\
\text { emotions }\end{array}$ & $\begin{array}{c}\text { Family } \\
\text { conflict }\end{array}$ \\
\hline $\begin{array}{l}\text { Pre-operative: } \\
\text { Mean } \pm \text { SD }\end{array}$ & $7.4 \pm 2.4$ & $3.7 \pm 1.6$ & $2.8 \pm 2.5$ \\
\hline $\begin{array}{l}\text { Post-operative: } \\
\text { Mean } \pm \text { SD }\end{array}$ & $4.3 \pm 3.4$ & $1.7 \pm 1.7$ & $1.3 \pm 2.0$ \\
\hline $\begin{array}{l}Z_{(\text {wSR })} \\
\text { P value }\end{array}$ & $\begin{array}{l}\mathrm{Z}=5.056 \\
<0.001^{*}\end{array}$ & $\begin{array}{l}\mathrm{Z}=4.702 \\
<0.001^{*}\end{array}$ & $\begin{array}{l}\mathrm{Z}=2.934 \\
<0.003^{*}\end{array}$ \\
\hline $\begin{array}{l}\text { Percentage } \\
\text { change: } \\
\text { Mean } \pm \text { SD }\end{array}$ & $-42.9 \pm 40.5$ & $-47.6 \pm 54.9$ & $-17.4 \pm 151.6$ \\
\hline
\end{tabular}

WSR: Wilcoxon Signed Ranks Test

*: Statistically significant $(\mathrm{p}<0.05)$

\section{DISCUSSION}

This study was conducted to assess the changes of OHRQoL among CSHCNs and their families before and 1 month after oral rehabilitation under GA using the P-CPQ and FIS in Alexandria, Egypt.

Many studies investigated the change in children's OHRQoL after oral rehabilitation under GA using several OHRQoL assessing instruments $(8,20$, 30). The questionnaires were self-completed by parent/caregiver to determine the frequency of various oral health impacts on quality of life of CSHCNs. Klassen et al. (25) in 2008 concluded that shorter versions of the P-CPQ and FIS were more useful to assess OHRQoL in young children. Also, Thomson et al 2013 (31) reported that the short version of those questionnaires had acceptable reliability, validity and responsiveness.

The most common Special Health Care Need (SHCN) from the results of this study was mental retardation and cerebral palsy, where children suffered from mental and physical impairments. This could indicate that complexity of the disability might play a major role in the severity of oral health status. This may be attributed to difficult brushing ability, associated with coordinated muscular movements impairment (32).

More than half of the caregivers were mothers (63.8\%). This indicated that mothers are the primary care giver of their CSHCNs in Egypt. Therefore, providing oral health education and preventive programs training to parents specially the mothers should be of prime importance to improve oral health status of CSHCNs.

The questionnaire was self-completed by parents/caregivers, the response of (do not know) was scored as 4. According to El-Meligy et al. (20) this score could reveal unawareness of parents/caregivers about quality of life related to the oral health problems of their children which may be correlated with poor quality of life. The exclusion of (do not know) response may lead to the loss of valuable data. They found that including (do not know) response produced optimal internal consistency of this questionnaire.

The majority of parents/caregivers (67\%) did not have education beyond high school. This is in accordance with results of Farsi et al. (30) in 2018. It suggested that parents were less informed about the importance of the oral health of their children rather than having poor parent/caregiver's care or neglect resulting in development of caries in their young children.

In the present study, a significant improvement in OHRQoL was reported by parents/caregivers of SCHCNs using the P-CPQ section. The percentage change of oral symptoms, functional limitations, emotional well-being and social well-being domains indicated that the best and major improvement was related to the oral symptoms domain while the least improvement was with social well-being domain. 
These results are in accordance with the results of Malden et al. (33) and Klaassen et al. (25). This improvement can be attributed to the immediate effect of oral rehabilitation on the oral symptoms like relief of pain, bad breath and food impaction.

The total score of P-CPQ revealed a significant post-operative improvement at $\mathrm{p}=0.001$. The percentage change of percent mean indicated the decrease of the total score post-operative and the better improvement of OHRQol.

The improvement regarding FIS section was significant for each domain at $\mathrm{p}=0.001$. The percentage change of parental- family activity, parental emotions and family conflict domains showed the best improvement was related to the parental emotions domains as the parents felt relief after the removal of the burden of oral symptoms and complications related to their CSHCNs and observing the improvement of their children quality of life. The total score of FIS section was also significant at $\mathrm{p}=0.001$. The percentage change of percent mean indicated the decrease of the total score post-operative and the significant improvement of OHRQol.

These results regarding the improvement of the FIS scores were supported by Farsi et al. (30) in 2018, who studied the improvement of OHRQol in CSHCNs compared to healthy children. They reported that the significant improvement in OHRQoL of CSHCNs group was greater among this group reflecting the demands and the burden of parenting CSHCNs. This burden can inflict considerable stress on parents/caregivers and can be referred to the need of parents/caregivers of CSHCNs to deal with more health issues with their children.

In the present study, the significant improvement after oral rehabilitation under GA in the OHRQoL of CSHCNs and their families demonstrated that the effect of the oral condition on the whole life of those children and their families is tremendous. Thus, more attention needs to be focused on the enormous relief that dental treatment gave to those children and their families.

The main limitation of this study was the use of convenience sample without untreated control group (without dental treatment) which was not possible due to ethical considerations. Another limitation could be the inability to use radiographs in dental diagnosis due to the health conditions of CSHCNs, and the short term follow up period.

The overall results of this study necessitated the rejection of the null hypothesis that there is no improvement of the OHRQoL of CSHCN after oral rehabilitation under GA.

\section{CONCLUSION}

Our study emphasizes that the OHRQoL of CSHCN markedly improved after oral rehabilitation under GA as well as their families indicating the importance of oral rehabilitation for those children.

\section{CONFLICT OF INTEREST}

The authors declare that they have no conflicts of interest.

\section{REFERENCES}

1-Lee GHM, McGrath C, Yiu CKY, King NM. Sensitivity and responsiveness of the Chinese ECOHIS to dental treatment under general anaesthesia. Community Dent Oral Epidemiol. 2011;39:372-7.

2-Kassebaum NJ, Bernabe' E, Dahiya M, Bhandari B, Murray CJL, Marcenes W. Global burden of untreated caries: a systematic review and metaregression. J Dent Res. 2015;94:650-8.

3-Auluck A. Oral health of poor people in rural areas of developing countries. J Can Dent Assoc. 2005;71:7535.

4-American Academy of Pediatric Dentistry. Definition of special health care needs. Pediatr Dent. 2017;38:16.

5-Goldson E, Louch G, Washington K, Scheu H. Guidelines for the care of the child with special health care needs. Adv Pediatr. 2006;53:165-82.

6-World Health Organization (WHO). World report on disability: World Health Organization. WHO Press, available

at:https:/www.who.int/disabilities/world_report/201 1/report.pdf?ua=1; 2011.

7-Wahdan IH, El-Nimr NA. Identifying children with Special Health Care Needs in Alexandria, Egypt. Pediatr Res. 2018;84:57-61.

8-Baens-Ferrer C, Roseman MM, Dumas HM, Haley SM. Parental perceptions of oral health-related quality of life for children with special needs: impact of oral rehabilitation under general anesthesia. Pediatr Dent. 2005;27:137-42.

9-Atar M, Krperich EJ. Systemic disorders and their influence on the development of dental hard tissues: a literature review. J Dent Educ. 2010;38:296-306.

10-Desai M, Messer LB, Calache H. A study of the dental treatment needs of children with disabilities in Melbourne, Australia. Aust Dent J. 2001;46:41-50.

11-Mitsea A, Karidis A, Donta-Bakoyianni C, Spyropoulos N. Oral health status in Greek children and teenagers, with disabilities. J Clin Pediatr Dent. 2002;26:111-8.

12-Bradley C, McAlister T. The oral health of children with down syndrome in Ireland. Spec Care Dentist. 2004;24:55-60. 
13-Anders PL, Davis EL. Oral health of patients with intellectual disabilities: a systematic review. Spec Care Dentist. 2010;30:110-7.

14-Oredugba FA, Akindayomi Y. Oral health status and treatment needs of children and young adults attending a day centre for individuals with special health care needs. BMC Oral Health. 2008;8:1-8.

15-Uo W. Oral Health Guidance for Dental Professionals children with special health care needs \& their caregivers. 2012. Available at: http://dental.washington.edu/wpcontent/media/sp_need_pdfs/Guidance-Dental.pdf.

16-Owens PL, Kerker BD, Zigler E, Horwitz SM. Vision and oral health needs of individuals with intellectual disability. Ment Retard Dev Disabil Res Rev. 2006;12:28-40.

17-Baghdadi ZD. Effects of dental rehabilitation under general anesthesia on children's oral health-related quality of life using proxy short versions of OHRQoL instruments. Scientific World Journal. 2014;23:1-5.

18-O'Sullivan EA, Curzon ME. The efficacy of comprehensive dental care for children under general anesthesia. Br Dent J. 1991;171:56-8.

19-Jamjoom MM, AlMalik MI, Holt RD, ElNassry A. Dental treatment under general anaesthesia at a hospital in Jeddah, Saudi Arabia. Int J Paediatr Dent. 2001;11:110-6.

20-El-Meligy O, Maashi M, Al-Mushayt A, Al-Nowaiser A, Al-Mubark S. The effect of full-mouth rehabilitation on oral health-related quality of life for children with special health care needs. J Clin Pediatr Dent. 2016;40:53-61.

21-Jokovic A, Locker D, Stephens M, Guyatt G. Agreement between mothers and children aged 11-14 years in rating child oral health-related quality of life. Community Dent Oral Epidemiol. 2003;31:335-43.

22-Locker D, Jokovic A, Stephens M, Kenny D, Tompson

B, Guyatt G. Family impact of child oral and oro-facial conditions. Community Dent Oral Epidemiol. 2002;30:438-48.

23-Jokovic A, Locker D, Stephens M, Kenny D, Tompson B, Guyatt G. Measuring parental perceptions of child oral health related quality of life. J Public Health Dent. 2003;63:67-72.
24-Jokovic A, Locker D, Stephens M, Kenny D, Tompson B, Guyatt G. Validity and reliability of a questionnaire for measuring child oral-health-related quality of life. J Dent Res. 2002;81:459-63.

25-Klaassen MA, Veerkamp JSJ, Hoogstraten J. Dental treatment under general anaesthesia: the short-term change in young children's oral-health-related quality of life. Eur Arch Paediatr Dent. 2008;9:130-7.

26-Lotfy H. Assessment of oral health related quality of life for children after full mouth rehabilitation under general anesthesia [master's thesis]. Alexandria: Alexandria University; 2014.

27-Daabiss M. American Society of Anaesthesiologists physical status classification. Indian $\mathrm{J}$ Anaesth. 2011;55:111-5.

28-World Health Organization. Oral health surveys: basic methods [e-book]. 5th ed. World Health Organization; 2013. Available from: https:// www.who.int/oral_health/publications/97892415486 49/en/

29-Wilcoxon F. Individual comparisons by ranking methods. Biometrics Bulletin. 1945;1:80-3.

30-Farsi DJ, Farsi NJ, El-Housseiny AA, Turkistani JM, Farsi NM. Impact of dental rehabilitation on oral health-related quality-of-life in healthy children and those with special health care needs. J Contemp Dent Pract. 2018;19:367-74.

31-Thomson WM, Foster Page LA, Gaynor WN, Malden $\mathrm{PE}$. Short-form versions of the Parental-Caregivers Perceptions Questionnaire and the Family Impact Scale. Community Dent Oral Epidemiol. 2013;41:441-50.

32-Unkel JH, Fenton SJ, Hobbs JG, Frere CL. Toothbrushing ability is related to age in children. ASDC J Dent Child. 1995;62:346-8.

33-Malden PE, Thomson WM, Jokovic A, Locker D. Changes in parent-assessed oral health-related quality of life among young children following dental treatment under general anaesthetic. Community Dent Oral Epidemiol. 2008;36:108-17. 